\title{
An Overview of Tuberculosis Chemotherapy - A Literature Review
}

\author{
Susmita Sarkar, Mavanur R. Suresh \\ Faculty of Pharmacy and Pharmaceutical Sciences, University of Alberta, Edmonton, Alberta, Canada. \\ Received, January 24, 2011; Revised, March 23, 2011; Accepted, April 18, 2011; Published, April 18, 2011.
}

\begin{abstract}
Tuberculosis (TB) is a major global health threat. The emergence of human immunodeficiency virus (HIV) and also multi drug resistant (MDR) and extremely drug resistant (XDR)-TB poses a vital challenge to the control of the disease. For the last 50 years, no new anti-TB drug has been discovered. This literature review provides a brief discussion of existing drugs and emerging drug targets, and also of the advantages of incorporating modern drug delivery systems and immune modulators in order to improve the existing treatment regimen in terms of better efficacy, reduced drug administration frequency, shortened period of treatment and reduced drug related toxicity. The investigation for a new drug target is essential to continue the battle against MDR and XDR-TB. However, owing to the enormous cost and time involved in new drug development, improvement of the existing treatment regimen is seen to be a valid alternative.
\end{abstract}

This article is open to POST-PUBLICATION REVIEW. Registered readers (see "For Readers") may comment by clicking on ABSTRACT on the issue's contents page.

\section{INTRODUCTION}

Tuberculosis (TB) is the leading cause of death by a single treatable infectious disease; killing approximately 5,000 people per day throughout the world as the World Health Organisation (WHO) reported 1.8 million deaths due to TB in 2008 (1). The bacteria involved is a member of Mycobacterium family which has over 60 species with only a few like Mycobacterium tuberculosis (Mtb), Mycobacterium leprae, Mycobacterium africanum and Mycobacterium avium that cause human diseases. Mtb can exist in the human body for a long time without showing any clinical symptoms; this phase is called the latent stage. Once the host's immune system becomes weakened, either because of age or concurrent disease, the bacteria attain virulent or turn to the active form. Human immunodeficiency virus (HIV) infection weakens the immune system, thereby facilitating the infection or reactivation of the TB bacteria. Co-infection with TB and HIV synergistically influence each other's progress, rendering the host vulnerable to death (2-3).

TB is highly contagious during the active stage of the disease and it can be caused by inhaling as low as 10 bacteria (4). After inhaling, these bacteria are mainly captured by the alveolar macrophages, but they can evade the host immune system and remain in the dormant stage for a long time and can then be reactivated to virulent form under the immune compromised conditions of the host. This is possible because Mtb can persist in slow growing as well as in fast growing stages and this unique characteristic of Mtb makes treatment challenging. Almost all the antibiotics work when the bacteria are actively dividing. In the intensive phase of TB treatment, the antibiotics mainly kill the rapidly growing bacteria, causing rapid sputum conversion, and eradicate the clinical symptoms. In order to kill the persistent or slow growing strains of Mtb, the continuation phase of the treatment is essential.

TB can be treated effectively by using the first line drugs (FLD) which are isoniazid (INH), rifampin (RIF), pyrazinamide (PZA) and ethambutol (ETH). But this first line therapy often fails to cure TB for several reasons. Firstly, the treatment regimen is long, consisting of an initial 2 months of intensive phase treatment with all four drugs, followed by the continuation phase for 4 months with INH and RIF. The lengthy therapy period with multi drug treatment results in a lack of compliance causing the treatment failure.

Corresponding Author: Mavanur.R.Suresh. Faculty of Pharmacy and Pharmaceutical Sciences, University of Alberta, Edmonton; Email: msuresh@pharmacy.ualberta.ca 


\section{Abbreviations:}

ETH, ethambutol; FLD, first line drugs; GSH, glutathione; HIV, human immune deficiency virus; IFN- $\gamma$, interferon-gamma; INH, isoniazid; MDR, multi drug resistant; MAC, Mycobacterium avium complex; Mtb, Mycobacterium tuberculosis; NP, nanoparticles; PLG, poly (DL-lactide-co-glycolide); PZA, pyrazinamide; RIF, rifampin; TB, tuberculosis; TNF- $\alpha$, tumour necrosis factor- $\alpha$; WHO, World Health Organisation; XDR, extremely drug resistant

This results in relapse and spread of the disease and also contributes to the emergence of drug resistant bacteria. Secondly, these first line anti-TB drugs have toxic effects including hepatotoxicity, neurotoxicity and strong drug-drug interaction, especially when administered with anti retroviral drugs. Thirdly, emergence of multi drug resistant (MDR) and extremely drug resistant (XDR) TB further complicates the situation. The patients with MDR and XDR have to be treated with second line drugs which are more toxic and expensive (50-200 times costlier than FLD) (5), with longer treatment schedules of up to 2 years. A cost analysis study conducted by the Colorado physicians, the total treatment cost for treating the drug susceptible TB is found to be approximately US $\$ 1,206$ per patient (6). The cost includes those of drugs and their administration, tests to evaluate treatment progress and also tests to assess hepatotoxicity; however, the figure does not include the patient's time cost. Another study conducted in Philippines, found the total cost for treating MDR-TB was around US $\$ 3,355$ per patient (7). Finally, after the initial intensive phase of the treatment, when the disease symptoms subside, many patients stop taking medication mainly because of high pill count and associated toxic effects. The discontinuation of therapy facilitates the emergence of MDR and XDR strains.

The emergence of MDR and XDR-TB underscore the necessity of a new line of tuberculosis drugs. A study conducted in South Africa reported an average 16 day survival, between diagnosis and death among the patients co-infected with XDR-TB and HIV (8). The discovery of the complete genome sequence of TB bacteria helped to identify several important drug targets (9) and fortunately, many new drugs are in the clinical trial stage. Currently, the approximate cost of developing a new drug is $\$ 800$ million to $\$ 1.7$ billion (10) with considerable involvement of time. This fact highlights the importance of improving the existing treatment options - in terms of shortening the treatment period, reducing the frequency of drug administration and associated toxicity, and also targeting the dormant population of the bacteria - in order to control the drug susceptible strain and thereby minimize the emergence of MDR and XDR-TB.

The initial part of this review focuses on the new and emerging drugs and their targets. In the latter part the focus shifts towards the two main ways to improve the existing treatment regimen exploiting modern drug delivery systems and incorporating immune modulators within the formulation. This cocktail formulation has the potential to solve many of the hurdles present in the existing TB therapy.

\section{Existing and Emerging Drugs: First line drugs:}

There has been a drought of new anti-TB drugs for more than 50 years. The drugs isoniazid (INH), rifampin (RIF), pyrazinamide (PZA) and ethambutol (ETH) are collectively called the first line of drugs (FLD). The FLDs work fine for drug susceptible strains of the bacteria, in fact until now INH and RIF are the two most effective drugs against Mtb. Among the available FLDs, only pyrazinamide can work on the persistant population of the bacteria (11) but none can kill the dormant population of the bacteria which cause latent disease and if left untreated can cause relapse of the disease under immune compromised condition. In many bacterial infections the small residual bacteria, left after antibiotic treatment, can be effectively killed by the host immune system. But that does not happen in TB (12) as the host is already in immune compromised condition and moreover the TB bacteria constantly manipulate around the host's already weakened immune system. So it takes usually 6 months to treat the disease if the bacteria are drug susceptible. The brief summary of individual FLDs, regarding their mode of action and activity, is shown in Table.1.

\section{New and emerging drugs: Fluoroquinolones:}

This class of drugs consists of ofloxacin, ciprofloxacin, gatifloxacin, moxifloxacin and many 
others. Though some of the drugs were discovered earlier but their anti TB activities have been reported recently. This group of drugs has good pharmacokinetic behaviour which may help to reduce the frequency of drug administration; they also can penetrate the tissues very well, including macrophages $(13,14)$ - the primary docking site for the TB bacteria. Their toxicity levels were also less adverse when administered alone (13). However, moxifloxacin, when administered along with RIF and PYZ, showed considerable toxic effects as it is well known that the latter two show fatal hepatotoxicity when used in combination (15). The combination regimen of these three showed better performance than INH, RIF and PYZ in the mouse model (16). The moxifloxacin is in phase 3 clinical trials undertaken by the TB Alliance Group (17). Many of the fluoroquinolones are used as second line drugs in TB patients but fluoroquinoloneresistant bacteria are emerging at a faster rate. In fact, in the Philippines, $51 \%$ of the MDR-TB cases were found to be resistant to both ciprofloxacin and ofloxacin (18).

\section{Rifamycin Derivatives:}

The easy way to determine a new compound having anti-TB activity is to try different derivatives of the existing FLDs with better pharmacokinetic behaviour, less toxicity and relatively new so that no resistant strain has evolved against it. One such derivative is rifamycin; this class of drugs contain rifabutin, rifalazil, rifapentine and many others. These compounds are a modified form of rifampicin (RIF). They are usually more active than the parent compound RIF. Rifabutin is 4-8 times more active than RIF against Mtb and has a longer half-life and good tissue penetration properties (19). Another major advantage of rifabutin over RIF is its relatively low level of drug interaction. The Center for Disease Control and Prevention (CDC) in the USA recommends rifabutin instead of RIF for simultaneous treatment of TB and HIV because of its better compatibility with other antiretroviral drug regimens than RIF $(20,21)$.

Rifalazil is particularly more potent against TB bacteria. In vitro activity of this drug is 100 times higher than RIF and also shows better in vivo activity in the mouse model. Better efficacy in humans has been reported for once weekly administration of it along with daily $\mathrm{INH}$, compared to daily administration of both RIF and INH without any significant adverse toxicity (22).

\section{Oxazolidinones:}

This group of compounds has broad spectrum antimicrobial activity and some of them are available in the market. These drugs exhibit good efficacy against Mtb in the mouse model. They work by inhibiting early protein synthesis in the bacteria, and the rate of emergence of resistant strain is usually slow (23-24). The second generation of oxazolidinones has less toxicity than the first generation, with similar anti-microbial activity. Linezolid and PNU-100480 both have shown good efficacy in the murine model (25). Linezolid sometimes has been used outside its label claim as an anti-TB drug in MDR and XDR-TB (25).

\begin{tabular}{|c|c|c|c|}
\hline Drug & Discovered & Mechanism of action (12) & Active against (11) \\
\hline Isoniazid (INH) & $\begin{array}{l}\text { Discovered in } 1912 \text { but } \\
\text { anti-TB activity } \\
\text { reported on } 1951\end{array}$ & $\begin{array}{l}\text { Inhibiting the cell wall } \\
\text { synthesis. }\end{array}$ & $\begin{array}{l}\text { Fast growing population of the } \\
\text { bacteria. }\end{array}$ \\
\hline Pyrazinamide (PZA) & 1952 & $\begin{array}{l}\text { Inhibiting and depleting the } \\
\text { membrane energy. }\end{array}$ & $\begin{array}{l}\text { Population of bacteria having } \\
\text { low metabolic activity and can } \\
\text { survive in acidic } \mathrm{pH} \text {. }\end{array}$ \\
\hline Rifampicin (RIF) & 1959 & $\begin{array}{l}\text { Inhibiting the nucleic acid } \\
\text { synthesis. }\end{array}$ & $\begin{array}{l}\text { Population with spurts of } \\
\text { metabolism: dormant with } \\
\text { occasional short, active period } \\
\text { of metabolism or growth }\end{array}$ \\
\hline Ethambutol (ETH) & 1961 & $\begin{array}{l}\text { Inhibiting the cell wall } \\
\text { synthesis. }\end{array}$ & $\begin{array}{l}\text { Fast growing population and } \\
\text { mainly used to minimise INH } \\
\text { resistance. }\end{array}$ \\
\hline
\end{tabular}




\section{Nitroimidazoles:}

The most effective drug in this group is nitroimidazopyran PA-824. It can simultaneously inhibit protein and lipid synthesis of the mycobacteria and exhibit bactericidal activity against both replicating and dormant populations of the bacteria (26). This drug has the potential to treat both active and latent $\mathrm{TB}$ and it is currently in Phase II trial taken by the TB Alliance (17). Like all nitroimidazoles, it is also mutagenic and carcinogenic but to a lesser extent than other parent compounds. This can be a major concern towards its development as a good anti-TB drug (27).

\section{Azole Drugs:}

The drugs like miconazole and clotrimizole are active against Mtb (28). They target the cytochrome P450 homologs in the bacteria. The subsequent crystallisation of Mtb cytochrome P450 enzyme system initiated studies to evaluate new drug (29).

\section{Diarylquinoline:}

TMC 207 is the lead compound of this series. It is effective against all the pathogenic strains of mycobacteria which cause TB. In addition it is equally effective in drug susceptible as well as drug resistant strains of the bacteria. That is why TMC 207 is the first ever TB drug that is in trial in both forms of TB (drug susceptible and resistant) by TB Alliance (30). Human studies with this drug have showed good efficacy in MDR-TB, with acceptable toxic effect (31). This drug targets a novel ATP synthase of the bacteria $(32,33)$

\section{Phenothiazines:}

Phenothiazines like chlorpromazine and thioridazine are antipsychotic drugs with considerable anti-TB activity (34-36). In vitro, they can inhibit both drug susceptible as well as drug resistant bacteria. Their anti-TB activity is partly due to their relative concentration in macrophages where there is a maximum concentration of the TB bacteria $(35,37-38)$.

\section{Peptide deformylase inhibitors:}

Peptide deformylase inhibitors is a metalloprotease enzyme essential for maturation of nascent polypeptides in bacteria but not essential for humans (39). This is a relatively new drug target having anti-TB activity and has the potential of a future drug target (40). In the BCG strain of $\mathrm{TB}$, this gene is absolutely vital for the bacteria's survival (41) but unfortunately this drug target has little effect on the slow growing TB bacteria (42).

\section{Some new emerging drug targets:}

Ever since the discovery of the complete genome sequence (9) of a virulent strain of TB bacteria, lots of new drug targets have been identified, and some of them are showing promise in animal models. The evaluation of new drug targets is essential to carry on the constant battle against the drug resistant strains of TB. Some of the recent and promising drug targets are discussed below:

The cell wall of Mtb is very important for the bacteria's survival within constrained conditions like the inside of human macrophages. The biosynthesis of the cell wall components involves many important stages and different enzymes (42, 43), and these enzymes are attractive drug targets. Another advantage of targeting this system is its absence in the mammalian system. Two of the important first line drugs, isoniazid and ethambutol, work by inhibiting the bacterial cell wall synthesis. The search is ongoing for new targets. Recently, the 2C-methyl-D-erythritol 4-phosphate (MEP) pathway was found to be an attractive one (44) and the drug fosmidomycin inhibits this pathway. This pathway has the potential for a good drug target since the end product of this pathway leads to the formation of isoprenoids, responsible for the synthesis of several cell wall components (45-47).

Mtb has a large repertoire of lipophilic molecules which is quite uncommon in the bacterial population. For example, E.coli has around 50 lipid metabolizing enzymes and the corresponding number for Mtb is roughly 250 which include many of the fat metabolizing enzymes found in plant and mammalian systems (42). This underscores the importance of this group of compounds in TB bacteria. Isocitrate lyase (ICL) is an important enzyme in this category and also an important drug target. ICL is involved in energy production via the metabolism of acetyl-CoA and propionyl-CoA. The inactivation of $\mathrm{Icl}$ gene leads to attenuation of both the persistent and virulent strains of TB bacteria (48). A recent study revealed that the bacteria even had a salvage pathway in the presence of ICL inhibitor, provided they can scavenge vitamin B12 from the host (49). These findings highlight the prospect of a good anti TB drug capable of blocking the main and salvage pathways, simultaneously. 
Amino acid biosynthesis is another important target for developing anti-TB drugs. The shikimate pathway is in particular very important. It is involved in the synthesis of the aromatic amino acids in the algae, fungi, bacteria and higher plants but it is absent in the mammalian system. This feature makes the pathway an attractive target for developing anti TB drugs with minimum cross reactivity (50). In fact, the inhibitor of this pathway acts as a promising herbicide and research is ongoing for developing an antimycobacterial drug by exploiting the enzymes involved in this pathway. The biosynthesis of non-aromatic amino acids is also an emerging drug target. The impact of amino acids like lysine, proline, tryptophan and leucine was evident from the fact that the Mtb strain, knocked out of the genes required for the biosynthesis of above mentioned amino acids, showed less virulence even in the severe combined immunodeficiency mouse model $(51,52)$.

The PhoPR is a two component signal transduction system found in mycobacteria and this system is vital for bacterial virulence. The PhoP mutant strain of Mtb showed less virulence (53). This mutant strain of Mtb also showed lesser secretion of ESAT-6 and CFP-10, two major immunodominant protein antigens present in pathogenic TB bacteria (54). The suitable inhibitor for this system can serve as an important drug for TB treatment.

The stringent response enzyme is essential for bacteria's long time survival within the host; therefore, targeting the enzyme can subsequently reduce the treatment period (55). Another important set of emerging drug targets is the components of the siderophore biosynthesis of Mtb (56). Upon infection, as a part of the defence mechanism, the host has several mechanisms to withdraw or control the free extracellular as well as intracellular iron concentration (57). The siderophores are high affinity iron chelating compounds present in bacteria that help them to acquire iron from the iron deficit environment of the host. The carboxymycobactins and mycobactins are two types of siderophore present in Mtb. An antibiotic named 5'-O-[N- (salicyl)sulfamoyl] adenosine was reported to block the biosynthesis of both and hence the replication of $\mathrm{Mtb}$, in vitro, under iron constrained conditions (58).
Role of Nanoparticles in Anti-TB Drug Delivery: A holistic review outlined the difficulties in assessing the treatment adherence towards anti TB therapy (59). The patients' compliance to the existing multi drug regimen for TB treatment is very poor and that leads to further complication of the disease condition. The poor compliance is caused by the prolonged treatment period and high daily pill count which also enhance the drug related toxicity. One of the major milestones to achieve good compliance rate is either to reduce the total period of drug treatment or to cut down the daily pill count. This can be achieved by incorporating sophisticated formulation techniques. Encapsulating the anti TB drugs within a micro or nanoparticle can greatly enhance the bioavailability of the drugs and thereby reduce the frequency of drug administration to, say, once weekly compared to the existing daily intake. This type of encapsulated formulation acts as a drug reservoir and slowly releases the drug over a prolonged period of time.

Synthetic as well as natural materials are used to design the particles. The synthetic components include poly (DL-lactide-co-glycolide) (PLG), poly lactic acid, poly glycolic acid etc and the natural components include liposome, alginic acid, chitosan, gelatin etc. The selection of the constituent material and the associated excipients are dependent upon the route of delivery, the required rate of drug release and the properties of the drugs to be encapsulated (60). The advantage of all the above mentioned components is their biodegradability so they are easily eliminated from the body.

\section{Synthetic nanoparticles material:}

Many groups of scientists are working on the advantage of incorporating anti TB drugs exploiting modern drug delivery systems. In a study conducted by Pandey et.al., three first line anti TB drugs, namely, INH, RIF and PYZ, were encapsulated in PLG nanoparticle (PLG-NP) and administered orally (once every 10 days) in Mtb infected mice. The pharmacokinetic parameters were compared with that of the daily free drug administration. In the group treated with PLG-NP, the minimum inhibitory concentration was maintained for 6-9 days in plasma and 9 days in organs (liver, lungs and spleen) but in the free drugs group, the same level was maintained for 12-24 hours only. No bacterial load was found in the PLG-NP treated 
group compared to the untreated mice (61). The same investigators found similar results when the study was conducted in the guinea pig model (62) and in the mouse model using inhalable PLG-NP (63). None of the studies found any sign of hepatotoxicity.

\section{Natural nanoparticles materials:}

In another study, INH and RIF were encapsulated in liposomes tagged with o-stearyl amylopectin and administered intravenously in infected mice. The ostearyl amylopectin tagging facilitates the targeting of the drug towards the lung tissue (64). The clearing of bacterial load was achieved within 6 weeks of drug administration (once weekly) and using $1 / 3^{\text {rd }}$ of their corresponding therapeutic dose with no sign of hepatotoxicity (65).

Similar kind of prolonged drug activity, with lower frequency of dose and lower amount of drug administration, was observed in the drugs encapsulated in alginic acid-chitosan nanoparticle (66). The major advantages of these natural materials over the synthetic polymers were discussed in a review by Pandey et.al (60). Briefly, the non requirement of any expensive organic solvents during the encapsulation step, higher aqueous matrix and high gel porosity are some of the advantages, and moreover some of the components are already approved for clinical use in different formulations (60). The current status of the nanoparticle research with TB drugs is discussed in details in a recently published review (67).

\section{Immune-Modulator In TB Therapy:}

In many other bacterial infections, the time required to treat the disease is comparably less because once the drug initiates the killing of the majority of the bacilli, the host immune system can take care of the residual bacilli. But this does not happen in TB, mainly because TB bacteria impair the host immune system (68). There are some well established TB antigens which can manipulate the host immune system $(69,70)$ and thereby render it incapable of fighting off the residual bacteria on its own. In order to counter balance this scenario, the incorporation of immune-modulators in the treatment regimen for $\mathrm{TB}$ seems to be a logical option.

\section{The cytokines as modulators:}

The cytokines are very powerful immunomodulators and different studies have shown their involvement during mycobacterial infections. Like all other bacterial infections, Th1 response, the intracellular cell mediated immunity, is vital for protection against TB infection. So the cytokines that promote the Th1 response should be able to provide better protection. IL-12 plays an important role towards the enhancement of Th1 response. During TB infection, IL-12 promotes the secretion of interferon-gamma (IFN- $\gamma$ ), tumour necrosis factor $\alpha$ (TNF- $\alpha$ ) and granulocytemacrophage colony-stimulating factor, all of them polarise the immune response towards Th1, via the activation of natural killer (NK) cells (71). The exogenous administration of IL-12 in mice showed enhanced resistance towards the intravenously infected Mtb bacteria (72). The IL-12 knockout mice showed higher susceptibility towards the mycobacterial infection (72). The defect or deletion in the IL-12 receptor gene leads enhanced susceptibility not only towards the pathogenic mycobacteria but also towards the non pathogenic mycobacteria including bacillus Calmette-Guérin (BCG) vaccine strain $(73,74)$. This condition is referred as Mendelian Susceptibility to Mycobacterial Disease, a disease caused by gene defect. The incorporation of IL-12 microsphere in the TB subunit vaccine showed enhanced immunity and protection (75). Enhanced treatment efficacy was obtained by concomitant use of rifabutin and clarithromycin along with IL-12 in severe combined immunodeficiency as well as in wild type mice in Mycobacterium avium complex (MAC) model (76). These findings underscore the crucial role of IL-12 during TB infection. However, tissue toxicity and induction of autoimmunity are two major concerns that limit the therapeutic use of IL-12. The researcher found that combined gene therapy with IL-12 and granulocyte-macrophage colonystimulating factor in the mouse hepatocellular carcinoma model resulted in increased efficacy with decreased toxicity (77).

IFN- $\gamma$ is another crucial immunomodulator that plays a vital role during TB infection, although there are contradictory findings in literature regarding the role of IFN- $\gamma$ in TB. Some older studies reported that IFN- $\gamma$ pre-treated human macrophages were more susceptible to TB-bacterial growth $(78,79)$. However, the researchers also 
found that IFN- $\gamma$ administration in aerosol form resulted in rapid recovery in MDR-TB patients (80). The administration of IFN- $\gamma$, along with anti-MAC drugs, showed better bacterial clearance profile in the MAC and AIDS co-infected patients (81). The difference in TB susceptibility in different populations had also been linked to polymorphism in the IFN- $\gamma$ gene (82-84).

TNF- $\alpha$, another crucial proinflammatory cytokine, activates macrophages to liberate nitric oxide synthase- 2 which is responsible for killing the intracellular $\mathrm{Mtb}(85,86)$. The mice deficient of TNF- $\alpha$ secretion and corresponding receptor showed higher susceptibility towards TB $(87,88)$. In humans, drug treatment with infleximab (a monoclonal antibody that inhibits TNF- $\alpha$ ) increases TB susceptibility (89).

IL-10 is an important immunosuppressive cytokine that can polarise the immune response towards T-helper cells of type 2 (Th2). The mouse macrophages infected with Mtb showed increased production of IL-10 which suppresses the production of Th1 promoting cytokine, IL-12 (90). In order to kill the bacteria residing within the cell, the Th1 cytokines which have intracellular access are absolutely essential. Many TB antigens have the property to switch the immune response towards the Th2 (70) and thereby able to survive within the cell. This response can be reversed by blocking the IL10 receptor. The incorporation of anti-IL-10 receptor antibody in the multi drug regimen of anti MAC treatment showed enhanced efficacy in the mouse model (91). A similar kind of enhanced Th1 response was also observed in the in vitro study with human peripheral blood mononuclear cell isolated from hepatitis $\mathrm{C}$ virus infected patients (92).

\section{Non-cytokine modulators:}

The incorporation of these immunomodulating cytokines in TB treatment may sound promising, but these cytokines occasionally lead to serious side effects and moreover, they are very expensive. Owing to the fact that tuberculosis is mainly concentrated in the resource constrained countries, the feasibility of incorporating these expensive cytokines in the treatment regimen is a debatable issue. This problem can be partially overcome by using simple chemical agents capable of doing the immunomodulation task like ATP and its analogs, picolinic acid, imidazoquinoline, calcitriol, the
Chinese traditional medicine Mao-Bushi-SaishinTo, heat killed Mycobacterium vaccae etc (71). The vitamin $\mathrm{D}$ and glutathione are two simple compounds also capable of doing so.

The benefit of vitamin D in TB patients is a long known fact. In the pre-antibiotic era, the TB patients were encouraged to have sun exposure and cod liver oil, both of which increase the vitamin D synthesis in the body (93-95). Some scientists traced the anti-TB property of vitamin D with toll like receptor signalling (96). The different polymorphism in vitamin $\mathrm{D}$ receptor gene showed varied susceptibility towards TB (94). Some studies also pointed out that vitamin $\mathrm{D}$ enhanced the production of cathelicidin, an antimicrobial polypeptide, which kills the bacteria $(94,97)$.

Glutathione (GSH), a tri-peptide synthesised in the human body, is capable of protecting the cell against oxidative damage by scavenging the reactive free radicals, reactive oxygen intermediates and various other oxidizing agents. In addition, GSH level in antigen presenting cells dictates the cytokine profile, either Th1 or Th2 (98). The lack of GSH promotes the Th2 cytokine secretion (98). A recent study found the lower level of GSH in patients with active pulmonary tuberculosis compared to the healthy human (99). Nitric oxide (NO) is an important killing agent for Mtb but NO has short biological activity and is rapidly converted to nitrate and nitrite, neither of which has the mycobacteriocidal activity. GSH acts as a carrier for NO by forming GSNO which subsequently delivers the effector NO to inhibit the bacterial growth (100). The role of GSH in the macrophage infected with Mtb was studied in vitro and the addition of Buthionine sulphoximine which specifically inhibits GSH synthesis, resulted in enhanced growth of bacteria (101). On the other hand, the incorporation of $\mathrm{N}$-acetyl cysteine, a glutathione precursor, in the Mtb infected human macrophages was found to inhibit significant bacterial growth (102). These findings suggest the favourable role of GSH in the treatment of TB, although further studies are required to establish the beneficial effect of GSH by co-administering it along with anti-TB drugs.

\section{The Proposed Cocktail Formulation:}

Almost all first line anti-TB drugs have limited aqueous solubility, stability and bioavailability when administered in oral solid or liquid dosage 
form (103). To overcome this problem, the existing oral formulations need to be administered in higher concentration so that the minimum inhibitory concentration in serum can be achieved to kill the bug. This higher drug content in turn worsens the related drug toxicity. This problem can be overcome by encapsulating the drugs along with the immune modulators in nanoparticles (as depicted in the figure 1). Depending upon the size of these particles and the route of administration, they can be phagocytosed by specific organelle. The particles in the size range of $1-10 \mu \mathrm{m}$ are found to be predominantly taken up by macrophages (104), the primary pool of TB bacteria in human host. The incorporation of the immune modulator can enhance the effectivity of the drug treatment. The encapsulated formulation will act as a drug reservoir by controlling the release of the drug which can be further controlled by the formulation technique. This kind of formulation has the potential to enhance the therapeutic efficacy of the existing TB therapy. This type of low dose formulation may restart the research for some good anti TB drug candidates whose trials were abandoned because of the toxicity at the higher dose.

The specific targeting can be further facilitated by surface decorating these particles with antibody against the specific surface markers present in macrophages. In human macrophages, the primary receptors for $\mathrm{Mtb}$ are the complement receptor and the mannose receptor (105). In addition to these receptors, several other surface markers for alveolar macrophages have been identified from patients with interstitial lung disease (106). The specific monoclonal antibodies against some of those markers can be used to decorate the surface of the drug bearing nanoparticles to facilitate its specific uptake by the alveolar macrophages. The specific targeting can enhance the maximum utilization of the total incorporated drug and therefore require less amount of drug to maintain the minimum inhibitory concentration. The less amount of drug incorporation and less systemic exposure of the drug will minimize the drug related toxicity compared to the existing oral formulations. This type of formulation has been tried in the tumour treatment (107) but never attempted in the treatment for TB.

\section{Expert Opinion}

In recent years, quite a number of compounds are in different stages of clinical trials. This was possible due to the harmonized efforts from various Working Groups under the STOP TB partnership along with public-private partnerships, and contributions from industry and academic researchers (108). The new compounds will be tested in combination with the established anti TB drugs to minimise the chance of developing drug resistance (108). The continuous research in this field will keep on adding more suitable drug candidates into the existing TB drug pipeline. The future looks promising in terms of evolving a new TB drug. To ensure this progress, continuous efforts and funding are vital together with adequate time.

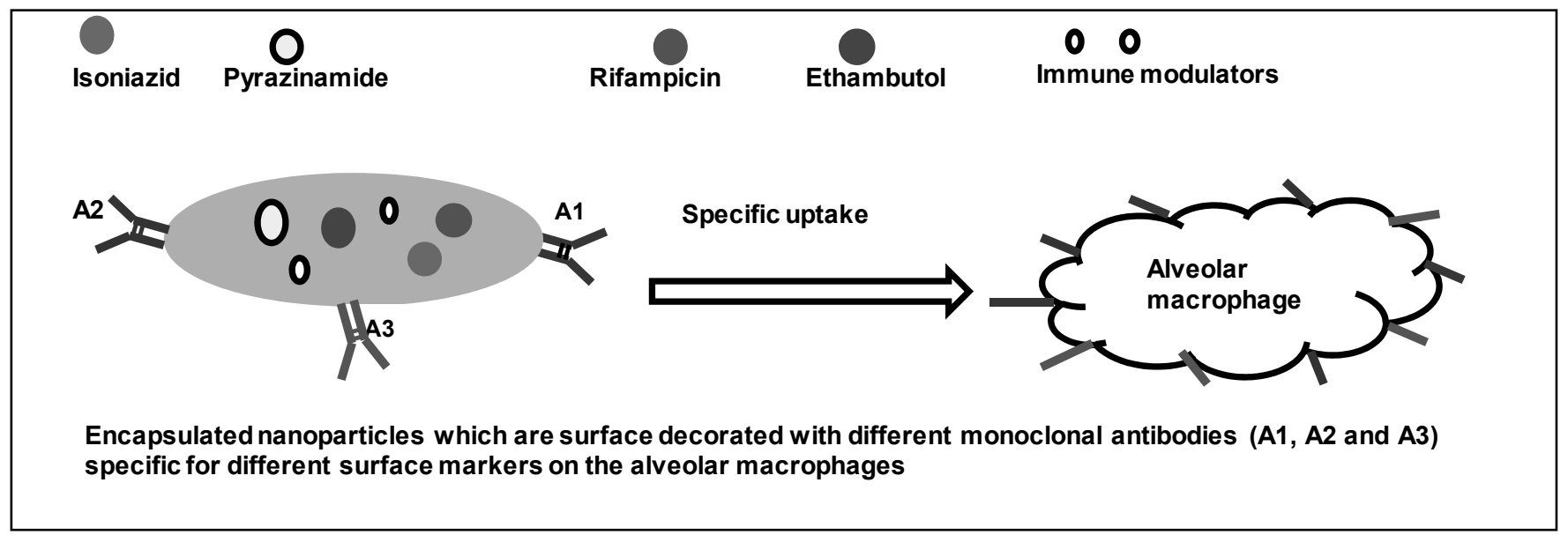

Figure 1. The schematic representation of the proposed cocktail formulation. 
A multifaceted approach is required to design a new and effective treatment regimen for TB. The new regimen should be able to address the followings:

$>\quad$ Maintain the required concentration of drugs in vivo for a comparatively long time thereby able to reduce the frequency of pill administration.

Maintain the correct amount of drug concentration at the exact target (alveolar macrophages) - thereby reducing the systemic toxicity.

$>\quad$ Target the actively dividing as well as dormant populations of the bacteria - thereby reducing the time required for the treatment.

$>$ Convenient in terms of administration, schedule, length and price - thereby enhancing the patient's compliance.

Modification of the existing treatment regimen might be useful to restrict the current spread of the disease. In this respect, incorporation of nanoparticles and immunoadjunctive agents, separately or in combination, look promising. There needs to be more studies done in order to standardize their efficacy and minimize toxicity when co-administered with anti TB drugs and also the price of the final formulation should be user friendly.

\section{CONCLUSION}

The chemotherapy of $\mathrm{TB}$ will almost always involve a cocktail of drugs because of the unique nature of the bacteria. It is difficult to design a single drug that can simultaneously kill the actively replicating, semi-dormant and dormant populations of the bacteria. Among the existing first line drugs, only pyrazinamide can effectively kill the slow growing population of the bacteria with minimum bactericidal effect on the fast growing population. The existing first line of treatment is the best available option for treating TB. The designing of new treatment regimens is very crucial to control the current spread of the TB which is the leading cause of death by a single, treatable, infectious disease (109).

There are some challenges towards the development of a new treatment regimen for TB. Firstly, the unavailability of a suitable animal model that can mimic the human disease profile. The mouse model is used widely. In most of the studies, the disease is artificially induced by using high dose of bacilli by different routes of inoculation. The reactivation of $\mathrm{TB}$, the major mode of $\mathrm{TB}$ infection in human, cannot be mimicked in the mouse model. Moreover, there is differential opinion regarding the nitric oxide killing mechanism in murine and human macrophages $(110,111)$. The mice also do not form caseous granuloma, the hallmark of human TB infection. Secondly, there is no suitable model that can mimic the latent stage of the Mtb. Though various models have been tried, like the Wayne model and starvation model etc, but none can exactly reflect the scenario observed in the latent stage of the disease in humans. In fact, the survival mechanism of bacteria in latent stage is not well understood. Thirdly, according to a recent study, it takes around $\$ 800$ million to $\$ 1.7$ billion to develop a drug from scratch and to bring it to the pharmacy shelf, with considerable involvement of time (10). Moreover, the stringent regulation criteria also deter the pharmacy companies from developing any new drug (112). Since TB is a problem mainly for resource constrained countries, initially there was less interest by the companies to invest in the development of new drugs. But because of the steadily deteriorating condition of TB, many nonprofit organisations came forward in recent years and that invigorated TB research. Finally, it is difficult to assess the efficacy of a new drug when it is administered along with numerous other anti-TB drugs.

Annually US\$16 billion is required to combat TB throughout the globe (108). Thus, if implementing the particle encapsulation with/without immunmodulators, as discussed before, can improve the existing treatment regimen then this option may be worthwhile to investigate. Moreover, better compliance with the treatment can reduce the chance of bacterial evolution towards the drug resistant strain by eradicating the bacteria at early stage. The discovery of a new chemotherapy regimen for $\mathrm{TB}$, either by introducing novel drugs or by modifying the existing ones, having the criteria discussed in this review, can revolutionise the entire global scenario of the disease.

\section{ACKNOWLEDGEMENT}

The authors acknowledge the Alberta Ingenuity Centre for Carbohydrate Science (AICCS), Canada 
for financial support. S.S thanks Susan Evans Davies for doing the grammatical corrections.

\section{REFERENCES}

1. WHO TB report: (website accessed on 15th July 2010.)

http://www.who.int/tb/publications/global_report/20 09/pdf/report_without_annexes.pdf .

2. Goletti D, Weissman D, Jackson RW, Graham NM, Vlahov D, Klein RS, Munsiff SS, LOrtona L, Cauda R, Fauci AS. Effect of Mycobacterium tuberculosis on HIV replication. Role of immune activation. J.Immunol, 1996; 157:1271-1278.

3. Mariani F, Goletti D, Ciaramella A, Martino A, Colizzi V, Fraziano M. Macrophage response to Mycobacterium tuberculosis during HIV infection relationships between macrophage activation and apoptosis. Curr Mol Med, 2001; 1:209-216.

4. Strohmeier GR, Fenton JM. Roles of lipoarabinomannan in the pathogenesis of tuberculosis. Microbes Infect, 1999; 1:709-717.

5. WHO multi/extremely drug resistant TB report 2010 last accessed on 15 Apr, 2010: http://whqlibdoc.who.int/publications/2010/9789241 599191_eng.pdf.

6. Burman WJ, Dalton CB, Cohn DL, Butler JRG, Reves RR. A cost-effectiveness analysis of directly observed therapy vs self-administered therapy for treatment of tuberculosis. Chest, 1997; 112:63-70.

7. Tupasi TE, Gupta R, Quelapio MI, Orillaza RB, Mira NR, Mangubat NV, Belen V, Arnisto N, Macalintal L, Arabit M, Lagahid JY, Espinal M, Floyd K. Feasibility and cost-effectiveness of treating multidrug resistant tuberculosis: a cohort study in the Philippines. PLoS Med, 2006; 3(9): e352.

8. Gandhi NR, Moll A, Sturm AW, Pawinski $\mathrm{R}$, Govender T, Lalloo U, Zeller K, Andrews J, Friedland G. Extensively drug-resistant tuberculosis as a cause of death in patients coinfected with tuberculosis and HIV in a rural area of South Africa. Lancet, 2006; 368:1575-1580.

9. Cole ST, Brosch R, Parkhill J, Garnier T, Churcher C, Harris D, Gordon SV, Eiglmeier K, Gas S, Barry III CE, Tekaia F, Badcock K, Basham D, Brown D, Chillingworth T, Connor R, Davies R, Devlin K, Feltwell T, Gentles S, Hamlin N, Holroyd S, Hornsby T, Jagels K, Krogh A, McLean J, Moule S, Murphy L, Oliver K, Osborne J, Quail MA, Rajandream MA, Rogers J, Rutter S, Seeger K, Skelton J, Squares R, Squares S, Sulston JE, Taylor K, Whitehead S, Barrell BG. Deciphering the biology of Mycobacterium tuberculosis from the complete genome sequence. Nature, 1998; 393:537544.
10. DiMasi JA, Hansen RW, Grabowski HG. The price of innovation: new estimates of drug development cost. J Health Econ., 2003; 22:151-186.

11. Mitchison D. Basic mechanism of chemotherapy. Chest, 1979; 76:771-781.

12. Zhang Y. The magic bullets and tuberculosis drug targets. Annu Rev Pharmacol Toxicol, 2005; 45:529-564.

13. Hooper DC, Wolfson JS. The fluoroquinolonones: pharmacology, clinical uses and toxicities in humans. Antimicro Agents Chemother, 1985; 28:716-721.

14. Alangaden GJ, Lerner SA. The clinical use of fluoroquinolones for the treatment of mycobacterial diseases. Clin Infect Dise, 1997; 25:1213-1221.

15. Centers for Disease Control and Prevention (CDC). Update: Fatal and severe liver injuries associated with rifampin and pyrazinamide for latent tuberculosis infection, and revisions in American Thoracic Society/CDC recommendations-United States, 2001. MMWR Morb Mortal Wkly Rep, 2001; 50:733-735.

16. Nuermberger EL, Yoshimatsu T, Tyagi S, O'Brien RJ, Vernon AN, Chaisson RE, Bishai WR, Grosset $\mathrm{JH}$. Moxifloxacin-containing regimen greatly reduces time to culture conversion in murine tuberculosis. Am J Respir Crit Care Med, 2004; 169:421-426.

17. TB Alliance annual report 2009 (last accessed on 15 Apr, 2010): http://www.tballiance.org/downloads/publications/T BA\%20Annual\%202009.pdf.

18. Grimaldo ER, Tupasi TE, Rivera AB, Quelapio MI, Cardano RC, Derilo JO, Belen VA. Increased resistance to ciprofloxacin and ofloxacin in multidrug-resistant Mycobacterium tuberculosis isolates from patients seen at a tertiary hospital in Philippines. Int J Tuberc Lung Dis, 2001; 5:546-550.

19. Brogden RN, Fitton A. Rifabutin. A review of its antimicrobial activity, pharmacokinetic properties and therapeutic efficacy. Drugs, 1994; 47:983-1009.

20. Centers for Disease Control and Prevention (CDC). Updated guidelines for the use of rifabutin or rifampin for the treatment and prevention of tuberculosis among HIV-infected patients taking protease inhibitors or nonnucleoside reverse transcriptase inhibitors. MMWR Morb Mortal Wkly Rep, 1999; 49:185-189.

21. Centers for Disease Control and Prevention (CDC). Prevention and treatment of tuberculosis among patients with human immunodeficiency virus: principles of therapy and revised recommendations. Centers for Disease Control and Prevention. MMWR Recomm Rep, 1998; 47:1-58.

22. Dietze R, Teixeira L, Rocha LM, Palaci M, Johnson JL, Wells C, Rose L, Eisenach K, Ellner JJ. Safety 
and bactericidal activity of rifalzil in patients with pulmonary tuberculosis. Antimicrob Agents Chemother, 2001; 45:1972-1976.

23. Moellering RC. Linezolid; the first oxazolidinone antimicrobial. Ann Intern Med, 2003; 138:135-142.

24. Bozdogan B, Appelbaum PC. Oxazolidinones: activity, mode of action, and mechanism of resistance. Int J Antimicrob Agents, 2004; 23:113119.

25. Williams KN, Stover CK, Tasneen TZR, Tyagi S, Grosset JH, Nuermberger E. Promising antituberculosis activity of the oxazolidinone PNU100480 relative to linezolid in the murine model. Am J Respir Crit Care Med, 2009; 180:371-376.

26. Stover CK, Warrener P, VanDevanter DR, Sherman DR, Arain TM, Langhorne MH, Anderson SW, Towell JA, Yuan Y, McMurray DN, Kreiswirth BN, Barry CE, Baker WR. A small-molecule nitroimidazopyran drug candidate for the treatment of tuberculosis. Nature, 2000; 405: 962-966.

27. Barry CE 3rd, Boshoff HI, Dowd CS. Prospects for clinical introduction of nitroimidazole antibiotics for the treatment of tuberculosis. Curr Pharm Des, 2004; 10:3239-3262.

28. Sun Z, Zhang Y. Antituberculosis activity of certain antifungal and antihelmintic drugs. Tuberc Lung Dis, 1999; 79:319-320.

29. Leys D, Mowat CG, McLean KJ, Richmond A, Chapman SK, Walkinshaw MD, Munro AW. Atomic structure of Mycobacterium tuberculosis CYP121 to 1.06 A reveals novel features of cytochrome P450. J Biol Chem, 2003; 278:51415147.

30. Diacon AH, Pym A, Grobusch M, Patientia R, Rustomjee R, Page-Shipp L, Pistorius C, Krause R, Bogoshi M, Churchyard G, Venter A, Allen J, Palomino JC, De Marez T, van Heeswijk RP,Lounis N, Meyvisch P, Verbeeck J, Parys W, de Beule K, Andries K, Mc Neeley DF. The Diarylquinoline TMC207 for multidrug-resistant tuberculosis. N Engl J Med, 2009; 360:2397-2405.

31. Andries K, Verhasselt P, Guillemont J, et al. A diarylquinoline drug active on the ATP synthase of Mycobacterium tuberculosis. Science, 2005; 307:223-227.

32. Koul A, Dendouga N, Vergauwen K, Molenberghs B, Vranckx L, Willebrords R, Ristic Z, Lill H, Dorange I, Guillemont J, Bald D, Andries K. Diarylquinolines target subunit $\mathrm{c}$ of mycobacterial ATP synthase. Nat Chem Biol, 2007; 3:323-324.

33. Amaral L, Kristiansen JE. Phenothiazines: an alternative to conventional therapy for the initial management of suspected multidrug resistant tuberculosis. A call for studies. Int $\mathrm{J}$ Antimicrob Agents, 2000; 14:173-176.
34. Amaral L, Kristiansen JE, Viveiros M, Atouguia J. Activity of phenothiazines against antibioticresistant Mycobacterium tuberculosis: a review supporting further studies that may elucidate the potential use of thioridazine as anti-tuberculosis therapy. J Antimicrob Chemother, 2001; 47:505511.

35. Amaral L, Kristiansen JE, Abebe LS, Millett W. Inhibition of the respiration of multi-drug resistant clinical isolates of Mycobacterium tuberculosis by thioridazine: potential use for initial therapy of freshly diagnosed tuberculosis. J Antimicrob Chemother, 1996; 38:1049-1053.

36. Bettencourt MV, Bosne-David S, Amaral L. Comparative in vitro activity of phenothiazines against multidrug-resistant Mycobacterium tuberculosis. Int J Antimicrob Agents, 2000; 16:6971.

37. Crowle AJ, Douvas GS, May MH. Chlorpromazine: a drug potentially useful for treating mycobacterial infections. Chemotherapy, 1992; 38:410-419.

38. Giglione C, Pierre M, Meinnel T. Peptide deformylase as a target for new generation, broad spectrum antimicrobial agents. Mol Microbiol, 2000; 36:1197-1205.

39. Sharma A, Khuller GK, Sharma S. Peptide deformylase - a promising therapeutic target for tuberculosis and antibacterial drug discovery. Expert Opin Ther Targets, 2009; 13:753-765.

40. Teo JW, Thayalan P, Beer D, Yap AS, Nanjundappa M, Ngew X, Duraiswamy J, Liung S, Dartois V, Schreiber M, Hasan S, Cynamon M, Ryder NS, Yang X, Weidmann B, Bracken K, Dick T,Mukherjee K. Peptide deformylase inhibitors as potent antimycobacterial agents. Antimicrob Agents Chemother, 2006; 50:3665-3673.

41. Hasan S, Daugelat S, Rao PS, Schreiber M. Prioritizing genomic drug targets in pathogens: application to Mycobacterium tuberculosis. PLos Comput Biol, 2006; 2:540-550.

42. Khasnobis S, Escuyer VE, Chatterjee D. Emerging therapeutic targets in tuberculosis: post- genomic era. Expert Opin Ther Targets, 2002; 6:21-40.

43. Brennan PJ, Crick DC. The cell-wall core of Mycobacterium tuberculosis in the context of drug discovery. Curr Top Med Chem, 2007; 7:475-488.

44. Eoh H, Brennan PJ, Crick DC. The Mycobacterium tuberculosis MEP (2C-methyl-D-erythritol 4phosphate) pathway as a new drug target. Tuberculosis, 2009; 89:1-11.

45. Wolucka BA, McNeil MR, de Hoffmann E, Chojnacki T, Brennan PJ. Recognition of the lipid intermediate for arabinogalactan/arabinomannan biosynthesis and its relation to the mode of action of ethambutol on mycobacteria. J Biol Chem, 1994; 269:23328-23335. 
46. Mahapatra S, Yagi T, Belisle JT, Espinosa BJ, Hill PJ, McNeil MR, Brennan PJ, Crick DC. Mycobacterial lipid II is composed of a complex mixture of modified muramyl and peptide moieties linked to decaprenyl phosphate. J Bacteriol, 2005; 187:2747-2757.

47. Anderson RG, Hussey H, Baddiley J. The mechanism of wall synthesis in bacteria. The organization of enzymes and isoprenoid phosphates in the membrane. Biochem J, 1972; 127:11-25.

48. Mckinney JD, Honer ZU, Bentrup K, Munoz-Elias EJ. Persistance of mycobacterium tuberculosis in macrophages and mice requires the glyoxalate shunt enzyme isocitrate lyase. Nature, 2000; 406:683-685.

49. Savi S, Warner DF, Kana BD, Mckinney JD, Mizrahi V, Dawes SS. Functional characterisation of a vitamin B12-depandent methylmalonyl pathway in mycobacterium tuberculosis: implications for propionate metabolism during growth on fatty acids. J Bacteriol, 2008, 190:3886-3895.

50. Ducati RG, Basso LA, Santos DS. Mycobacterial shikimate pathway enzymes as targets for drug design. Current Drug Targets, 2007; 8:423-435.

51. Pavelka MS Jr, Chen B, Kelley CL, Collins FM, Jacobs WR Jr. Vaccine efficacy of alysine auxotroph of Mycobacterium tuberculosis. Infect Immun, 2003; 71:4190-4192.

52. Smith DA, Parish T, Stoker NG, Bancroft GJ. Characterization of auxotroph mutants of Mycobacterium tuberculosis and their potential as vaccine candidates. Infect Immun, 2001; 69:11421150.

53. Ryndak M, Wang S, Smith I. PhoP, a key player in Mycobacterium tuberculosis virulence. Trends Microbiol, 2008; 16:528-534.

54. Frigui W, Bottai D, Majlessi L, Monot M, Josselin E, Brodin P, Garnier T, Gicquel B, Martin C, Leclerc C, Cole ST, Brosch R. Control of M.tuberculosis ESAT-6 secretion and specific T cell recognition by PhoP. PLoS Pathog, 2008; 4:e33.

55. Primm TP, Anderson SJ, Mizrahi V, Avarbock D, Rubin H, Barry CE III. The stringent response of Mycobacterium tuberculosis is required for longterm survival. J Bacteriol, 2000; 182:4889-4898.

56. Monfeli RR, Beeson C. Targeting iron acquisition by Mycobacterium tuberculosis. Infect Disord Drug Targets, 2007; 7:213-220.

57. Weinberga ED, Miklossy J. Iron withholding: a defense against disease. J Alzheimers Dis, 2008; 13:451-463.

58. Ferreras JA, Ryu JS, Di Lello F, Tan DS, Quadri LE. Small-molecule inhibition of siderophore biosynthesis in Mycobacterium tuberculosis and Yersinia pestis. Nat Chem Biol, 2005; 1:29-32.

59. Munro SA, Lewin SA, Smith HJ, Engel ME, Fretheim A, Volmink J. Patient adherence to tuberculosis treatment: a systematic review of qualitative research. PLoS Med, 2007; 4:e238.

60. Pandey R, Khuller GK. Nanotechnology based drug delivery system(s) for the management of tuberculosis. Indian J Exp Biol, 2006; 44:357-366.

61. Pandey R, Ahmed Z, Sharma S, Khuller GK. Nanoparticle encapsulated antituberculosis drugs as a potential oral drug delivery system against murine tuberculosis. Tuberculosis (Edinb), 2003; 83: 373378.

62. Sharma A, Pandey R, Sharma S, Khuller GK. Chemotherapeutic efficacy of poly (DL-lactide-coglycolide) nanoparticle encapsulated antituberculosis drugs at sub-therapeutic dose against experimental tuberculosis. Int J Antimicrob Agent, 2004; 24:599604.

63. Pandey R, Sharma A, Zahoor A, Sharma S, Khuller GK, Prasad B. Poly (DL-lactide-co-glycolide) nanoparticle based inhalable sustained drug delivery system for experimental tuberculosis. J Antimicrob Chemother, 2003; 52:981-986.

64. Deol P, Khuller GK. Lung specific stealth liposomes; stability, biodistribution and toxicity of liposomal antituberculosis drugs in mice. Biochem Biophys Acta; 1997: 1334:161-172.

65. Pandey R, Sharma S, Khuller GK. Liposome based antituberculosis drug therapy in a guinea pig model of tuberculosis. Int J Antimicrob Agents, 2004; 23:414-415.

66. Pandey R, Khuller GK. Chemotherapeutic potential of alginate chitosan microspheres as antitubercular drug carriers. J Antimicrob Chemother, 2004; 53: 635-640.

67. Shegokar R, Al Shaal L, Mitri K. Present status of nanoparticle research for treatment of Tuberculosis. J Pharm Pharm Sci, 2011; 14: 100-116.

68. Canetti G. The Tubercle bacillus in the pulmonary lesion of man. New York: Springer. 1955.

69. Briken V, Porcelli SA, Besra GS, Kremer L. Mycobacterial lipoarabonamannan and related lipoglycans: from biogenesis to modulation of the immune response. Mol Microbiol, 2004; 53:391403.

70. Jozefowski S, Sobota A, Kwiatkowska K. How Mycobacterium tuberculosis subverts host immune responses. Bio Essays, 2008; 30:943-954.

71. Tomioka H. Adjunctive immunotherapy of mycobacterial infections. Current Pharm Design, 2004; 10:3297-3312.

72. Cooper AM, Magram J, Ferrante J, Orme IM. Interleukin 12 (IL-12) is crucial to the development of protective immunity in mice intravenously infected with Mycobacterium tuberculosis. J Exp Med, 1997; 186:39-45. 
73. Altare F, Durandy A, Lammas D et.al. Impairment of mycobacterial immunity in human interleukin 12 receptor defiency. Science, 1998; 280:1432-1435.

74. Casanova JL. Mendelian susceptibility to mycobacterial infection in man. Swiss Med Wkly, 2001, 131:445-454.

75. Ha SJ, Park SH, Kim HJ, Kim SC, Kang HJ, Lee EG, Kwon SG, Kim BM, Lee SH, Kim WB, Sung YC, Cho SN. Enhanced immunogenicity and protective efficacy with the use of interleukin-12encapsulated microspheres plus AS01B in tuberculosis subunit vaccination. Infect Immun, 2006; 74:4954-4959.

76. Doherty TM, Sher A. IL-12 promotes drug-induced clearance of Mycobacterium avium infection in mice. J Immunol, 1998; 160:5428-5435.

77. Wang Z, Qiu SJ, Ye SL, Tang ZY and Xiao X. Combined IL-12 and GM-CSF gene therapy for murine hepatocellular carcinoma. Cancer Gene Ther, 2001; 8:751-758.

78. Douvas GS, Looker DL, Vatter AE, Crowel AJ. Interferon- $\gamma$ activates human macrophages to become tumoricidal and leishmanicidal but enhances duplication of macrophage-associated mycobacteria. Infect Immunol, 1985; 50:1-8.

79. Rook GAW, Steele J, Ainsworth M, Champion BR. Activation of macrophages to inhibit proliferation of Mycobacterium tuberculosis: comparison of the effects of recombinant gamma interferon on human monocytes and murine peritoneal macrophage. Immunology, 1986; 59:333-338.

80. Condos R, Rom WN, Schluger NW. Treatment of multidrug-resistant pulmonary tuberculosis with interferon gamma via aerosol. Lancet, 1997; 349:1513-1515.

81. Squires KE, Brown ST, Armstrong D, Murphy WF, Murray HW. Interferon-gamma treatment for Mycobacterium avium intracellulre complex bacillemia in patients with AIDS. J Infect Dis, 1992; 166:686-687.

82. Newport MJ, Awomoyi AA, Blackwell JM. Polymorphism in the interferon-gamma receptor-1 gene and susceptibility to pulmonary tuberculosis in the Gambia. Scand J Immunol, 2003; 58:383-385.

83. Cooke GS, Campbell SJ, Sillah J, Gustafson P, Bah B, Sirugo G, Bennett S, McAdam KP, Sow O, Lienhardt C, Hill AV. Polymorphism within the interferon-gamma/receptor complex is associated with pulmonary tuberculosis. Am J Respir Crit Care Med, 2006; 174:339-343.

84. Stein CM, Zalwango S, Chiunda AB, Millard $\mathrm{C}$, Leontiev DV, Horvath AL, Cartier KC, Chervenak K, Boom WH, Elston RC, Mugerwa $\mathrm{RD}$, Whalen $\mathrm{CC}$, Iyengar SK. Linkage and association analysis of candidate genes for TB and TNF alpha cytokine expression: evidence for association with IFNGR1, IL-10, and TNF receptor 1 genes. Hum Genet, 2007; 121:663-673.

85. Ding AH, Nathan CF, Stuehr DJ. Release of reactive nitrogen intermediates and reactive oxygen intermediates from mouse peritoneal macrophages. Comparison of activating cytokines and evidence for independent production. J Immunol, 1988; 141:2407-2412.

86. Flesch IE, Hess JH, Oswald IP, Kaufmann SH. Growth inhibition of Mycobacterium bovis by IFNgamma stimulated macrophages: regulation by endogenous tumour necrosis factor-alpha and by IL10. Int Immunol, 1994; 6:693-700.

87. Bean AG, Roach DR, Briscoe H, France MP, Korner H, Sedgwick JD, Britton WJ. Structural deficiencies in granuloma formation in TNF genetargeted mice underlie the heightened susceptibility to aerosol Mycobacterium tuberculosis infection, which is not compensated for by lymphotoxin. J Immunol, 1999; 162:3504-3511.

88. Flynn JL, Goldstein MM, Chan J, Triebold KJ, Pfeffer K, Lowenstein CJ, Schreiber R, Mak TW, Bloom BR. Tumor necrosis factor-alpha is required in the protective immune response against Mycobacterium tuberculosis in mice. Immunity, $1995 ; 2: 561-572$.

89. Keane J, Gershon S, Wise RP, Mirabile-Levens E, Kasznica J, Schwieterman WD, Siegel JN, Braun MM. Tuberculosis associated with infliximab, a tumour necrosis factor alphaneutralizing agent. $\mathrm{N}$ Engl J Med, 2001; 345:1098-1104.

90. Hickman SP, Chan J, Salgame P. Mycobacterium tuberculosis induces differential cytokine production from dendritic cells and macrophages with divergent effect on naive T cell polarization. J Immunol, 2002; 168:4636-4642.

91. Silva RA, Pais TF, Appelberg R. Blocking the receptor for IL-10 improves antimycobacterial chemotherapy and vaccination. J Immunol, 2001; 167:1535-1541.

92. Rigopoulou EI, Abbot WGH, Haigh P, Naoumov NV. Blocking the interleukin-10 receptor- a novel approach to stimulate T-helper cell type 1 responses to hepatitis $C$ virus. Clin Immunol, 2005; 117:57-64.

93. Selvaraj P, Chandra G, Jawahar MS, Rani MV, Rajeshwari DN, Narayanan PR. Regulatory role of vitamin D receptor gene variants of Bsm I, Apa I, Taq I, and Fok I polymorphisms on macrophage phagocytosis and lymphoproliferative response to Mycobacterium tuberculosis antigen in pulmonary tuberculosis. J Clin Immunol, 2004; 24:523-532.

94. Chocano-Bedoya P, Ronnenberg AG. Vitamin D and tuberculosis. Nutr Rev, 2009; 67:289-293.

95. Martineau AR, Honecker FU, Wilkinson RJ, Griffiths CJ. Vitamin D in the treatment of 
pulmonary tuberculosis. J Steroid Biochem Mol Biol, 2007; 103:793-798.

96. Liu PT, et al. Toll-like receptor triggering of a vitamin D-mediated human antimicrobial response. Science, 2006; 311:1770-1773.

97. Harvard gazette archives (last accessed on $25 \mathrm{Apr}$, 2010):

http://www.news.harvard.edu/gazette/2006/03.09/01 -tb.html.

98. Peterson JD, Herzenberg LA, Vasquez K, Waltenbaugh C. Glutathione levels in antigenpresenting cells modulate Th1 versus Th2 response patterns. Proc Nat Acad Sci USA, 1998; 95:30713076.

99. Venketaraman V, Millman A, Salman M, Swaminathan S, Goetz M, Lardizabal A, David Hom, Connell ND. Glutathione levels and immune responses in tuberculosis patients. Microb Pathog, 2008; 44:255-261.

100.Connell ND, Venketaraman V. Control of Mycobacterium tuberculosis infection by glutathione. Recent Pat Antiinfect Drug Discov, 2009; 4:214-226.

101.Venketaraman V, Dayaram YK, Talaue MT, Connell ND. Glutathione and nitrosoglutathione in macrophage defense against $M$. Tuberculosis. Infect Immunity, 2005; 73:1886-1894.

102. Venketaraman V, Rodgers T, Linares R, Reilly $\mathrm{N}$, Swaminathan S, Hom D, Millman AC, Wallis $\mathrm{R}$, Connell ND. Glutathione and growth inhibition of Mycobacterium tuberculosis in healthy and HIV infected subjects. AIDS Res Therap, 2006; 3:5.

103. Barrow WW. Microsphere technology for chemotherapy of mycobacterial infections. Curr Pharm Des, 2004; 10:3275-3284.
104.Barrow ELW, Winchester GA, Staas JK, Quenelle DC, Barrow WW. Use of microsphere technology for sustained and targeted delivery of rifampin to Mycobacterium tuberculosis- infected macrophages. Antimicrob Agents Chemother, 1998; 42:26822689.

105. Schlesinger LS. Macrophage phagocytosis of virulent but not attenuated strains of Mycobacterium tuberculosis is mediated by mannose receptors in addition to complement receptors. J Immunol, 1993; 150:2920-2930.

106.Taylor ML, Noble PW, White B, Wise R, Liu MC and Bochner BS. Extensive surface phenotyping of alveolar macrophages in interstitial lung disease. Clin Immunol, 2000; 94:33-41.

107.Akasaka Y, Ueda H, Takayama K, Machida Y, Nagai T. Preparation and evaluation of bovine serum albumin nanospheres coated with monoclonal antibodies. Drug Des Deliv, 1988; 3:85-97.

108.TB Alliance website (last accessed on $26^{\text {th }}$ March 2011): http://www.tballiance.org/newscenter/viewinnews.php?id $=546$

109. Dye C. Global epidemiology of tuberculosis. Lancet, 2006; 367:938-940.

110. Schneemann M, Schoedon G, Hofer S, Blau N, Guerrero L, Schaffner A. Nitric oxide synthase is not a constituent of the antimicrobial armature of human mononuclear phagocytes. J Infect Dis, 1993; 167:1358-1363.

111.MacMicking J, Xie Q, Nathan C. Nitric oxide and macrophage function. Ann Rev Immunol, 1997; 15:323-350.

112. Kalia VC, Rani A, Lal S, Cheema S, Raut CP. Combing databases reveals potential antibiotic producers. Exp Opin Drug Disc, 2007; 2:211-224. 